\title{
Interaction between functional health literacy, patient activation, and glycemic control
}

\author{
This article was published in the following Dove Press journal: \\ Patient Preference and Adherence \\ 24 July 2014 \\ Number of times this article has been viewed
}

\section{LeChauncy D Woodard \\ Cassie R Landrum \\ Amber B Amspoker \\ David Ramsey \\ Aanand D Naik}

Veterans Affairs Health Services Research and Development Effectiveness and Safety, Michael E

DeBakey Veterans Affairs Medical

Center, and Section of Health

Services Research, Department of Medicine, Baylor College of Medicine,
Center for Innovations in Quality, Houston, TX, USA
Correspondence: LeChauncy DWoodard MEDVAMC 152, 2002 Holcombe Blvd,

Houston, TX 77030, USA

Tel + I 7I3 $440444 \mid$

Fax +I 7137487359

Email lwoodard@bcm.edu
Background: Functional health literacy (FHL) and patient activation can impact diabetes control through enhanced diabetes self-management. Less is known about the combined effect of these characteristics on diabetes outcomes. Using brief, validated measures, we examined the interaction between FHL and patient activation in predicting glycosylated hemoglobin $\left(\mathrm{HbA}_{1 c}\right)$ control among a cohort of multimorbid diabetic patients.

Methods: We administered a survey via mail to 387 diabetic patients with coexisting hypertension and ischemic heart disease who received outpatient care at one regional VA medical center between November 2010 and December 2010. We identified patients with the study conditions using the International Classification of Diseases-Ninth Revision-Clinical Modification (ICD-9-CM) diagnoses codes and Current Procedure Terminology (CPT) procedures codes. Surveys were returned by $195(50.4 \%)$ patients. We determined patient activation levels based on participant responses to the 13-item Patient Activation Measure and FHL levels using the single-item screening question, "How confident are you filling out medical forms by yourself?" We reviewed patient medical records to assess glycemic control. We used multiple logistic regression to examine whether activation and FHL were individually or jointly related to $\mathrm{HbA}_{1 \mathrm{c}}$ control.

Results: Neither patient activation nor FHL was independently related to glycemic control in the unadjusted main effects model; however, the interaction between the two was significantly associated with glycemic control (odds ratio 1.05 [95\% confidence interval 1.01-1.09], $P=0.02$ ). Controlling for age, illness burden, and number of primary care visits, the combined effect of these measures on glycemic control remained significant (odds ratio 1.05 [95\% confidence interval 1.01-1.09], $P=0.02$ ).

Conclusion: The interaction between FHL and patient activation is associated with $\mathrm{HbA}_{1 \mathrm{c}}$ control beyond the independent effects of these parameters alone. A personalized approach to diabetes management incorporating these characteristics may increase patient-centered care and improve outcomes for patients with diabetes.

Keywords: health literacy, diabetes mellitus, self-care, veterans

\section{Introduction}

Diabetes mellitus affects nearly 26 million adults in the United States, with 1.9 million new cases diagnosed annually. ${ }^{1}$ Many patients with diabetes experience adverse vascular events, including myocardial infarction, peripheral arterial disease, and blindness. ${ }^{2}$ Diabetes control, characterized by reductions in glycosylated hemoglobin $\left(\mathrm{HbA}_{1 \mathrm{c}}\right)$, blood pressure, and cholesterol levels, is directly associated with decreased morbidity and mortality associated with diabetes. ${ }^{3}$ Diabetes self-management skills, including diet and exercise programs, glycemic monitoring, and adherence to complex medication regimens, contribute to diabetes control and reduction of diabetes-related morbidity. ${ }^{4}$

Patient activation, ie, involvement in treatment selection, planning, and implementation, is critical for managing diabetes in primary care, as defined by national standards 
from the American Diabetes Association, ${ }^{5}$ the Veterans Administration (VA) Department of Defense Management of Diabetes Mellitus Clinical Practice Guidelines, ${ }^{6}$ and the American Association of Clinical Endocrinologists. ${ }^{7}$ Patients with lower levels of activation have poorer diabetes selfmanagement and medication adherence than those with higher activation. ${ }^{8,9}$ Similarly, those with lower levels of functional health literacy (FHL), another patient characteristic associated with the capacity to perform self-management tasks, experience worse diabetes-related outcomes than those with higher FHL levels. ${ }^{10,11}$ Although the independent effects of FHL and patient activation are well documented, less is known about the combined effect of these two variables on diabetes outcomes. Understanding patients' FHL and activation levels may guide collaborative goal setting, ${ }^{12}$ which is an important step for improving blood pressure ${ }^{13}$ and glycemic control $^{14}$ in patients with diabetes. Using brief, validated screening measures, we explored the relationship between FHL, patient activation, and glycemic control in a cohort of multimorbid patients with diabetes receiving care at an established patient-centered medical home in one regional VA medical center.

\section{Materials and methods}

\section{Study population}

Using International Classification of Diseases-Ninth RevisionClinical Modification (ICD-9-CM) diagnosis codes and ICD-9-CM and Current Procedure Terminology codes, we identified patients with coexisting diabetes, hypertension, and ischemic heart disease who received outpatient care between November 10, 2010 and December 8, 2010. Patients were eligible for study participation if they had one inpatient diagnosis code or two outpatient diagnosis codes for each of the study conditions recorded in VA databases and had an identified VA patient-aligned care team, which is the VA model for the patient-centered medical home. ${ }^{15} \mathrm{We}$ also used relevant cardiovascular procedure codes to identify patients with ischemic heart disease. We reviewed each eligible patient's VA electronic medical record to confirm their disease history. We excluded patients with a documented limited life expectancy, ${ }^{16}$ those who died during the study period, and those with a diagnosis of dementia within 2 years of the beginning of the study.

\section{Data collection}

We mailed to eligible participants an introductory cover letter describing the study along with a self-administered survey that included brief measures of $\mathrm{FHL}^{17}$ and patient activation, ${ }^{18}$ as well as sociodemographic and clinical characteristics. We also provided a stamped envelope in which to return the survey. To increase the response rate, we remailed the materials once to those who did not return the survey within 4 weeks of the initial mailing. Patients who returned the survey received $\$ 20$, and we considered them to be enrolled participants. We sent surveys to 387 patients who met the inclusion criteria. From this sample, we received 195 (50.4\%) completed surveys. We collected demographic, laboratory, and clinical data from the electronic medical records of all VA patients who met our eligibility requirements and returned valid surveys. We used the Diagnostic Cost Group (DCG) relative risk score, a measure of patient burden of illness, to define clinical complexity. ${ }^{19}$ The DCG relative risk score is a ratio of the patient's predicted cost to the average actual cost of the VA population. A score of 1.00 represents the cost of an "average" patient, whereas a DCG relative risk score $<1.00$ represents a lower-than-average cost (and illness burden), and a score $>1.00$ represents a higher-than-average illness burden. To assess for nonresponse bias, we compared the sociodemographic characteristics of patients who returned completed surveys with the sociodemographic characteristics of those who did not. ${ }^{20}$

\section{Main measures}

We used a brief, single-item screen for FHL developed by Chew et al. ${ }^{21}$ Patients who responded "none of the time", "a little of the time", or "some of the time" to the question "How confident are you filling out medical forms by yourself?" were classified as having low FHL. This measure has been validated in patients with diabetes ${ }^{22}$ and across multiple VA samples with correlations to criterion measures of FHL, including the Rapid Estimate of Adult Literacy in Medicine and Test of Functional Health Literacy in Adults, short form. ${ }^{17,21}$ We examined patient activation using the Patient Activation Measure (PAM), which is positively associated with future utilization and diabetes outcomes, including HbA $_{1 \mathrm{c}}$ levels. ${ }^{9}$

We determined activation levels based on participant responses to the 13 -item PAM survey. ${ }^{18}$ The survey items assess patients' skill, confidence, and knowledge with regard to managing issues related to their health care. Responses to each question range from 1 to 4 , in ascending order for activation. To determine the overall patient activation score, we calculated the sum of individual responses, which ranged from 13 to 52 among study participants. Participants with a PAM score $\leq 38$ (mean item score $<3$ ) were classified as having low activation. PAM scores were normalized, 
converting the maximum low activation score to 52.9 and the range of scores to $0-100 .{ }^{18}$ We obtained each patient's most recent $\mathrm{HbA}_{1 \mathrm{c}}$ reading from his/her medical records. We assessed $\mathrm{HbA}_{1 \mathrm{c}}$ control according to American Diabetes Association guidelines. ${ }^{5}$

\section{Statistical analyses}

We examined associations between glycemic control and patient demographic and clinical characteristics using independent samples Student's $t$-tests and chi-square tests. A multiple logistic regression model was used to determine whether activation and FHL (interval-level variables) were individually and/or jointly related to $\mathrm{HbA}_{1 \mathrm{c}}$ control. The maineffects model included only activation and FHL as predictors; whereas the interaction model included these terms, as well as the interaction between activation and FHL. The concordance statistic (c) and the likelihood ratio chi-square value were calculated to assess discrimination and overall goodness of fit of each multivariate model. We conducted a second (adjusted) set of multiple logistic regression models, controlling for any demographic or clinical characteristics significantly associated with $\mathrm{HbA}_{1 \mathrm{c}}$ control. We also included age a priori in the adjusted model, given its clinical importance in determining
$\mathrm{HbA}_{1 \mathrm{c}}$ goals. All analyses were conducted in SAS version 9.3 (SAS Institute, Cary, NC, USA).

\section{Results}

Among the 195 returned surveys, we included 183 (94\%) participants who had complete and valid data for all variables included in these analyses. The mean age of the study cohort was 68 years. Almost one third were nonwhite (28\%). Most were married (61\%), had significant illness burden (DCG relative risk score of 2.7), and had multiple (4.8 in prior year) primary care visits (Table 1). Overall, approximately half ( $\mathrm{n}=90,49.2 \%$ ) of the participants had $\mathrm{HbA}_{1 \mathrm{c}}$ levels $<7.0 \%$. There was no difference in sociodemographic characteristics (eg, age, sex, and race) between survey responders and nonresponders (all $P>0.05$, data not shown).

Table 1 also compares participants' demographic and clinical characteristics by $\mathrm{HbA}_{1 \mathrm{c}}$ control. Illness burden, as measured by DCG relative risk score, was associated with $\mathrm{HbA}_{1 \mathrm{c}}$ control, with uncontrolled patients having higher illness burden than controlled patients (mean 3.25 \pm 3.89 and mean 2.22 \pm 2.87 , respectively). Similarly, the number of primary care visits was related to $\mathrm{HbA}_{1 \mathrm{c}}$ control, with uncontrolled patients having a greater number of visits than

Table I Participant demographic and clinical characteristics by $\mathrm{HbA}_{\mathrm{lc}}$ control

\begin{tabular}{|c|c|c|c|c|c|}
\hline & $\begin{array}{l}\text { Total } \\
(n=183)\end{array}$ & $\begin{array}{l}\mathrm{HbA}_{\mathrm{lc}}<7 \\
(\mathrm{n}=90)\end{array}$ & $\begin{array}{l}\mathrm{HbA}_{\mathrm{lc}} \geq 7 \\
(\mathrm{n}=93)\end{array}$ & $\begin{array}{l}\text { Student's } t \text {-test/ } \\
\chi^{2} \text { test statistic }\end{array}$ & $P$-value* \\
\hline Age, years & $67.9(7.89)$ & $68.53(8.64)$ & 67.31 (7.08) & -1.047 & 0.296 \\
\hline Relative risk & $2.74(3.45)$ & $2.22(2.87)$ & $3.25(3.89)$ & 2.039 & 0.043 \\
\hline Primary care visits & $4.83(3.72)$ & $3.88(3.24)$ & $5.75(3.93)$ & 3.525 & 0.001 \\
\hline PAM score & $37.96(6.44)$ & $38.62(7.21)$ & $37.32(5.55)$ & -1.368 & 0.173 \\
\hline Confidence with forms & $3.73(1.23)$ & $3.91(1.16)$ & $3.55(1.27)$ & -2.018 & 0.045 \\
\hline \multicolumn{6}{|l|}{ Sex, n (\%) } \\
\hline Male & 182 (99.5\%) & 89 (98.9\%) & $93(100.0 \%)$ & 1.039 & 0.492 \\
\hline Female & $\mathrm{I}(0.5 \%)$ & I (I.I\%) & $0(0.0 \%)$ & & \\
\hline \multicolumn{6}{|l|}{ Race, n (\%) (n=I79) } \\
\hline White & $128(7 \mid .5 \%)$ & $65(73.0 \%)$ & $63(70.0 \%)$ & 0.532 & 0.766 \\
\hline Black & $44(24.6 \%)$ & $20(22.5 \%)$ & $24(26.7 \%)$ & & \\
\hline Other & $7(3.9 \%)$ & $4(4.5 \%)$ & $3(3.3 \%)$ & & \\
\hline \multicolumn{6}{|l|}{ Marital status, $n(\%)(n=|8|)$} \\
\hline Married & 110 (60.9\%) & $54(60.7 \%)$ & $56(60.9 \%)$ & 0.001 & 0.979 \\
\hline Single/divorced/widowed & 71 (39.1\%) & $35(39.3 \%)$ & $36(39.1 \%)$ & & \\
\hline \multicolumn{6}{|l|}{ PAM categories, $\mathrm{n}(\%)^{\dagger}$} \\
\hline Low & IOI (55.2\%) & $43(47.8 \%)$ & $58(62.4 \%)$ & 3.936 & 0.047 \\
\hline High & $82(44.8 \%)$ & $47(52.2 \%)$ & $35(37.6 \%)$ & & \\
\hline \multicolumn{6}{|c|}{ Confidence with forms categories, $\mathrm{n}(\%)^{\ddagger}$} \\
\hline Low & $59(32.2 \%)$ & $21(23.3 \%)$ & 38 (40.9\%) & 6.431 & 0.011 \\
\hline High & $124(67.8 \%)$ & $69(76.7 \%)$ & 55 (59.1\%) & & \\
\hline
\end{tabular}

Notes: Data are shown as the mean and standard deviation, unless otherwise indicated. *Independent samples Student's $t$-test or $\chi^{2}$ test. ${ }^{\dagger}$ Activation score is sum of 13 Likert-scale questions with a range of $\mathrm{I}-4$. Score range is $13-52$; those with a normalized score of $\leq 52.9$ (per-question mean $<3$ ) were classified as having low activation. ¥Confidence with forms, single Likert-scale question with a range of I-5; those reporting scores of I-3 were classified as having low FHL.

Abbreviations: FHL, functional health literacy; $\mathrm{HbA}_{\mathrm{Ic}}$, glycosylated hemoglobin; PAM, Patient Activation Measure. 
Table 2 Unadjusted and adjusted multiple logistic regression models predicting glycemic control*

\begin{tabular}{|c|c|c|c|c|c|c|c|c|}
\hline & \multicolumn{4}{|c|}{ Unadjusted model } & \multicolumn{4}{|l|}{ Adjusted model } \\
\hline & OR (95\% Cl) & $P$-value & C & $\operatorname{LR} \chi^{2}$ & OR (95\% CI) & $P$-value & C & $\operatorname{LR} \chi^{2}$ \\
\hline \multicolumn{9}{|l|}{ Main-effects model } \\
\hline Relative risk & $N / A$ & N/A & 0.61 & $\chi^{2}(2)=4.37, P=0.11$ & $0.97(0.88,1.07)$ & 0.57 & 0.69 & $\chi^{2}(5)=16.19, P=0.006$ \\
\hline Age & $N / A$ & N/A & & & I.0I $(0.97,1.05)$ & 0.66 & & \\
\hline Number of PC visits & $N / A$ & $N / A$ & & & $0.87(0.79,0.96)$ & 0.006 & & \\
\hline Activation & I.0I $(0.96,1.07)$ & 0.58 & & & $1.02(0.96,1.07)$ & 0.59 & & \\
\hline $\mathrm{FHL}$ & $1.24(0.95,1.63)$ & 0.12 & & & $1.18(0.89,1.57)$ & 0.25 & & \\
\hline \multicolumn{9}{|l|}{ Interaction model** } \\
\hline Activation $\times \mathrm{FHL}$ & $1.05(1.01,1.09)$ & 0.019 & 0.62 & $\chi^{2}(3)=10.48, P=0.01$ & 1.05 (I.01, I.09) & 0.024 & 0.69 & $\chi^{2}(6)=21.75, P=0.001$ \\
\hline
\end{tabular}

Notes: *I, controlled $\mathrm{HbA}_{\mathrm{l}}(<7.0) ; 0$, uncontrolled $\mathrm{HbA}_{\mathrm{lc}}(\geq 7.0)$ modeled the likelihood of control; **Interaction models include all predictors from the main effects model with addition of activation by FHL interaction term; estimates for individual predictors are from main effects models, whereas estimates for the activation $\times \mathrm{FHL}$ predictors are from the interaction models.

Abbreviations: $\mathrm{C}$, concordance statistic; $\mathrm{LR} \chi^{2}$, likelihood ratio chi-square test of overall model fit; $\mathrm{Cl}$, confidence interval; HbA ${ }_{I c}$, glycosylated hemoglobin; OR, odds ratio; PC, primary care; FHL, functional health literacy; N/A, not available.

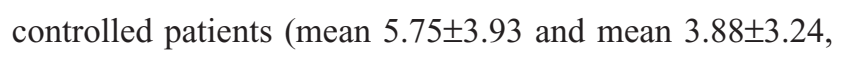
respectively). Further, controlled patients reported greater confidence with forms than uncontrolled patients (mean $3.91 \pm 1.16$ and mean 3.55 \pm 1.27 , respectively).

Although neither activation nor FHL was significantly related to glycemic control in the unadjusted main-effects model (likelihood ratio $\chi^{2}(2)=4.37, P=0.11$ ), the interaction between the two in the complete model was significant (odds ratio 1.05 [95\% confidence interval 1.01-1.09], $P=0.02$; likelihood ratio $\chi^{2}(3)=10.48, P=0.01$ ), and remained significant in the adjusted model that controlled for age, illness burden, and number of primary care visits (odds ratio 1.05 [95\% confidence interval 1.01-1.09], $P=0.02$, likelihood ratio $\chi^{2}(6)=21.75, P=0.001$ ) (see Table 2 ). The interaction is graphed in Figure 1 according to simple slopes. Values are graphed at one standard deviation above and below activation and FHL means. Those with higher activation scores are more likely to have controlled $\mathrm{HbA}_{1 \mathrm{c}}$, but only when they also have higher FHL.

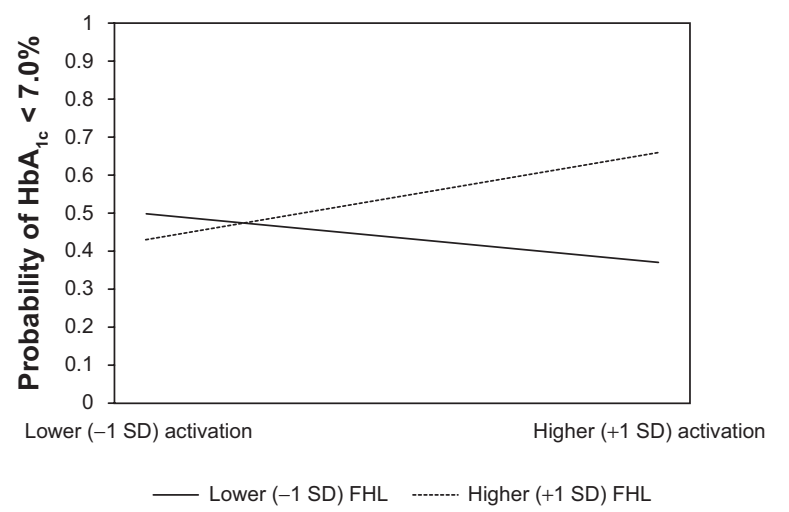

Figure I Simple slopes for the interaction of $\mathrm{FHL}$ and patient activation levels on the probability of having an $\mathrm{HbA}_{\mathrm{Ic}}$ level $<7 \%$.

Note: solid indicates lower (-I SD) FHL; dashed line indicates higher (+I SD) FHL. Abbreviations: FHL, functional health literacy; $\mathrm{HbA}_{1 \mathrm{c}}$, glycosylated hemoglobin; $\mathrm{SD}$, standard deviation.

\section{Discussion}

In this study, we assessed the relationship between FHL, activation, and $\mathrm{HbA}_{1 \mathrm{c}}$ control among multimorbid patients with diabetes receiving care within an established patientcentered medical home. We found that brief, validated measures of FHL and activation are feasible to obtain among patients within the context of primary care encounters. Further, we found that the combined effect of FHL and patient activation is predictive of better $\mathrm{HbA}_{1 \mathrm{c}}$ control beyond the independent effects of FHL or patient activation alone. These findings persisted after adjusting for age, illness burden, and number of primary care encounters, suggesting that understanding levels of FHL and patient activation may allow better personalization of diabetes self-management interventions, offering a more patientcentered approach to diabetes care.

Self-management interventions often focus on didactic education rather than personalized treatment goals and cultivation of problem-solving skills (action plans). ${ }^{23}$ Collaborative goal setting is an evidence-based method of engaging patients in diabetes self-management centered on personal goals and action plans. ${ }^{24}$ We have previously demonstrated that a group-based, primary care intervention to help patients set highly effective, evidence-based diabetes goals had a positive impact on goal-setting ability, diabetes self-efficacy, and $\mathrm{HbA}_{1 \mathrm{c}}$ levels. ${ }^{25,26}$ Patients who participated in the goal-setting intervention sustained $\mathrm{HbA}_{1 \mathrm{c}}$ improvements for 9 months after the active intervention, in contrast with the typical finding of regression to baseline levels within 4 months after completing traditional diabetes education sessions. ${ }^{27}$ However, in that study, additional improvements in goal-setting quality were not seen when participants returned to routine primary care; and the maintenance of goal-setting activities remained modest at 1 year among intervention participants, 
suggesting the need to further refine the collaborative goalsetting program. ${ }^{26}$

Integrating patient-centered characteristics, such as FHL and activation levels, may further personalize the collaborative goal-setting process and improve its long-term effectiveness. Validated, practical measures of FHL and activation levels exist. However, they are often not integrated into routine practice or shown to impact patient outcomes longitudinally. Without brief, validated measures, health care providers frequently have difficulty identifying patients with limited FHL. ${ }^{28,29}$ Delivering personalized FHL and activation data during patient-clinician encounters may enhance patient-centered communication and decision-making. ${ }^{30}$ In a study by Seligman et a ${ }^{31}$ physicians who were notified of the limited FHL in patients with diabetes prior to a visit reported greater use of strategies to improve communication about disease management, but were less satisfied with encounters because of feelings of inadequacy about using FHL information. Importantly, participating physicians received little education about how to use FHL information to guide interactions. ${ }^{31}$ Therefore, greater awareness and training on how to interpret and integrate measures of FHL and patient activation are needed.

Historically, the primary care visit has not provided an ideal setting to develop or support self-management skills through collaborative goal setting because of time constraints and multiple competing demands. ${ }^{32}$ However, the transition by many medical practices and health care organizations to the patient-centered medical home model of care ${ }^{15}$ offers an excellent opportunity to efficiently and effectively integrate diabetes self-management training and support into routine primary care practice. ${ }^{33} \mathrm{With}$ appropriate training, personnel in a patient-centered medical home can use information about patients' reported FHL and activation levels to personalize goals and action plans within patients' particular limitations and preferences for involvement. ${ }^{8,34}$

Despite our important findings, the current study has limitations. Participation in the study was limited to veterans receiving care at one regional VA medical center, which may limit generalizability. In addition, patients receiving care in the VA are overwhelmingly male, and male patients, in general, have been shown to have lower health literacy and patient activation levels than female patients. ${ }^{18,35}$ Thus, our findings may have differed in a sample with a greater proportion of women. Further, in contrast with prior studies that found independent associations between FHL and activation levels on diabetes outcomes, ${ }^{9,10}$ we found that only the interaction of these two characteristics was predictive of glycemic control which may reflect differences in the Veteran patient population and may not be representative of all patients with diabetes. Our survey was administered by mail; and, thus, nonresponders may have included a disproportionate number of patients who experience difficulty completing forms, possibly indicating lower levels of health literacy in this group. However, when we compared sociodemographic characteristics of responders with those of nonresponders, we found no significant differences.

Our findings suggest that a personalized approach to diabetes management incorporating patient-centered characteristics, such as FHL and activation levels, may result in more patient-centered care and improved diabetes outcomes. Future research is needed to inform how brief, valid measures of FHL and activation can be incorporated into routine diabetes self-management.

\section{Acknowledgments}

This work was supported by a Veterans Affairs Health Services Research and Development (VA HSR\&D) pilot grant PPO 09-316 (LDW) and the Houston VA HSR\&D Center for Innovations in Quality, Effectiveness, and Safety (CIN13-413). The authors are grateful to Sylvia Hysong for assistance with development of the survey, and to Tracy Urech and Omolola Adepoju, all of the Houston VA HSR\&D Center for Innovations in Quality, Effectiveness and Safety for assistance with manuscript review.

\section{Disclosure}

The authors report no conflicts of interest in this work.

\section{References}

1. American Diabetes Association. Data from the 2011 National Diabetes Fact Sheet. Available from: http://www.diabetes.org/diabetes-basics/ statistics/. Accessed May 17, 2014.

2. US Centers for Disease Control and Prevention. National Diabetes Fact Sheet, 2011. Available from: http://www.cdc.gov/DIABETES/pubs/ factsheet11.htm. Accessed May 17, 2014.

3. Snow V, Weiss KB, Mottur-Pilson C. Clinical Efficacy Assessment Subcommittee of the American College of Physicians. The evidence base for tight blood pressure control in the management of type 2 diabetes mellitus. Ann Intern Med. 2003;138(7):587-592.

4. Norris SL, Lau J, Smith SJ, Schmid CH, Engelgau MM. Self-management education for adults with type 2 diabetes: a meta-analysis of the effect on glycemic control. Diabetes Care. 2002;25(7):1159-1171.

5. Funnell MM, Brown TL, Childs BP, et al. National standards for diabetes self-management education. Diabetes Care. 2009;32 Suppl 1: S87-S94.

6. Pogach LM, Brietzke SA, Cowan CL, et al. Development of evidencebased clinical practice guidelines for diabetes: the Department of Veterans Affairs/Department of Defense guidelines initiative. Diabetes Care. 2004;27 Suppl 2:B82-B89. 
7. Garber AJ, Abrahamson MJ, Barzilay JI, et al. American Association of Clinical Endocrinologists' comprehensive diabetes management algorithm 2013 consensus statement - executive summary. Endocr Pract. 2013;19(3):536-557.

8. Hibbard JH, Greene J, Tusler M. Improving the outcomes of disease management by tailoring care to the patient's level of activation. Am J Manag Care. 2009;15(6):353-360.

9. Remmers C, Hibbard J, Mosen DM, Wagenfield M, Hoye RE, Jones C. Is patient activation associated with future health outcomes and health care utilization among patients with diabetes? J Ambul Care Manage. 2009;32(4):320-327.

10. Schillinger D, Grumbach K, Piette J, et al. Association of health literacy with diabetes outcomes. JAMA. 2002;288(4):475-482.

11. Fransen MP, von Wagner C, Essink-Bot ML. Diabetes self-management in patients with low health literacy: ordering findings from literature in a health literacy framework. Patient Educ Couns. 2012;88(1):44-53.

12. Naik AD, Street RL, Castillo D, Abraham NS. Health literacy and decision making styles for complex antithrombotic therapy among older multimorbid adults. Patient Educ Couns. 2011;85(3):499-504.

13. Naik AD, Kallen MA, Walder A, Street RL. Improving hypertension control in diabetes mellitus: the effects of collaborative and proactive health communication. Circulation. 2008;117(11):1361-1368.

14. Heisler M, Cole I, Weir D, Kerr EA, Hayward RA. Does physician communication influence older patients' diabetes self-management and glycemic control? Results from the Health and Retirement Study (HRS). J Gerontol A Biol Sci Med Sci. 2007;62(12):1435-1442.

15. Rosland AM, Nelson K, Sun H, et al. The patient-centered medical home in the Veterans Health Administration. Am J Manag Care. 2013; 19(7):e263-e272.

16. Woodard LD, Landrum CR, Urech TH, Profit J, Virani SS, Petersen LA. expectancy: implications for performance measurement. J Am Geriatr Soc. 2012;60(2):193-201.

17. Chew LD, Bradley KA, Boyko EJ. Brief questions to identify patients with inadequate health literacy. Fam Med. 2004;36(8):588-594.

18. Hibbard JH, Mahoney ER, Stockard J, Tusler M. Development and testing of a short form of the patient activation measure. Health Serv Res. 2005;40(6 Pt 1):1918-1930.

19. Petersen LA, Pietz K, Woodard LD, Byrne M. Comparison of the predictive validity of diagnosis-based risk adjusters for clinical outcomes. Med Care. 2005;43(1):61-67.

20. Halbesleben JR, Whitman MV. Evaluating survey quality in health services research: a decision framework for assessing nonresponse bias. Health Serv Res. 2013;48(3):913-930.

21. Chew LD, Griffin JM, Partin MR, et al. Validation of screening questions for limited health literacy in a large VA outpatient population. $J$ Gen Intern Med. 2008;23(5):561-566. Treating chronically ill people with diabetes mellitus with limited life

22. Jeppesen KM, Coyle JD, Miser WF. Screening questions to predict limited health literacy: a cross-sectional study of patients with diabetes mellitus. Ann Fam Med. 2009;7(1):24-31.

23. Brown VA, Bartholomew LK, Naik AD. Management of chronic hypertension in older men: an exploration of patient goal-setting. Patient Educ Couns. 2007;69(1-3):93-99.

24. Schulman-Green DJ, Naik AD, Bradley EH, McCorkle R, Bogardus ST. Goal setting as a shared decision making strategy among clinicians and their older patients. Patient Educ Couns. 2006;63(1-2):145-151.

25. Teal CR, Haidet P, Balasubramanyam AS, Rodriguez E, Naik AD. Measuring the quality of patients' goals and action plans: development and validation of a novel tool. BMC Med Inform Decis Mak. 2012;12:152.

26. Naik AD, Palmer N, Petersen NJ, et al. Comparative effectiveness of goal setting in diabetes mellitus group clinics: randomized clinical trial. Arch Intern Med. 2011;171(5):453-459.

27. Gonzales R, Handley MA. Improving glycemic control when "usual" diabetes care is not enough. Arch Intern Med. 2011;171(22):1999-2000.

28. Lindau ST, Basu A, Leitsch SA. Health literacy as a predictor of follow-up after an abnormal Pap smear: a prospective study. $J$ Gen Intern Med. 2006;21(8):829-834.

29. Bass PF, Wilson JF, Griffith CH, Barnett DR. Residents' ability to identify patients with poor literacy skills. Acad Med. 2002;77(10): 1039-1041.

30. Naik AD. On the road to patient centeredness. JAMA Intern Med. 2013; 173(3):218-219.

31. Seligman HK, Wang FF, Palacios JL, et al. Physician notification of their diabetes patients' limited health literacy. A randomized, controlled trial. J Gen Intern Med. 2005;20(11):1001-1007.

32. Østbye T, Yarnall KS, Krause KM, Pollak KI, Gradison M, Michener JL. Is there time for management of patients with chronic diseases in primary care? Ann Fam Med. 2005;3(3):209-214.

33. Piette JD, Holtz B, Beard AJ, et al. Improving chronic illness care for veterans within the framework of the Patient-Centered Medical Home: experiences from the Ann Arbor Patient-Aligned Care Team Laboratory. Transl Behav Med. 2011;1(4):615-623.

34. Sudore RL, Landefeld CS, Pérez-Stable EJ, Bibbins-Domingo K, Williams BA, Schillinger D. Unraveling the relationship between literacy, language proficiency, and patient-physician communication. Patient Educ Couns. 2009;75(3):398-402.

35. Greenberg E, Jin Y. US Department of Education. 2003 National Assessment of Adult Literacy: Public-Use Data File User's Guide (NCES 2007-464). National Center for Education Statistics, 2007. Available from: http://nces.ed.gov/naal/pdf/2007464.pdf. Accessed May 17, 2014.

\section{Dovepress}

\section{Publish your work in this journal}

Patient Preference and Adherence is an international, peer-reviewed, open access journal that focuses on the growing importance of patient preference and adherence throughout the therapeutic continuum. Patient satisfaction, acceptability, quality of life, compliance, persistence and their role in developing new therapeutic modalities and compounds to optimize

clinical outcomes for existing disease states are major areas of interest for the journal. This journal has been accepted for indexing on PubMed Central. The manuscript management system is completely online and includes a very quick and fair peer-review system, which is all easy to use. Visit http://www dovepress.com/testimonials.php to read real quotes from published authors. 